\title{
PENGARUH GROWTH OPPORTUNITY, PROFITABILITY, BUSINESS RISK DAN SIZE TERHADAP STRUKTUR MODAL (Studi Pada Perusahaan Property dan Real Estate Yang Terdaftar Di BEI Periode 2009-2017)
}

\author{
Ashop Barqoya ${ }^{1)}$ \\ 1)Program Pacasarjana pamulang, email : ashopfr@gmail.com
}

\section{ARTICLES}

INFORMATION

ABSTRACT

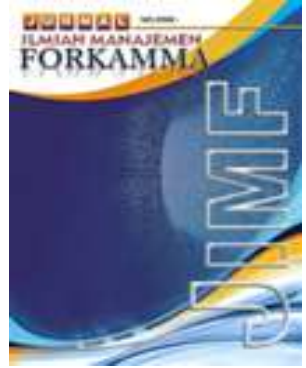

\section{JURNAL ILMIAH MANAJEMEN FORKAMMA}

\author{
Vol.2, No.3, Juli 2019 \\ Halaman : $89-99$ \\ (c) LPPM \& FORKAMMA
}

Prodi Magister Manajemen

UNVERSITAS PAMULANG

ISSN (online) : 2599-171X

ISSN (print) : : 2598-9545

\section{Keyword :}

growth opportunity, profitability, business risk, size, and capital structure

JEL. classification :

C33, G20, G23, N65

\section{Contact Author :}

\section{PRODI}

\section{MAGISTER MANAJEMEN \&}

\section{FORKAMMA UNPAM}

JL.Surya Kencana No.1 Pamulang

Tangerang Selatan - Banten

Telp. (021) 7412566, Fax (021) 7412491

Email :

jurnalforkamma.unpam@gmail.com
The purpose of this study was to determine the effect of growth opportunity, profitability, business risk, and size on the company's capital structure either partially or simultaneously. The object of research used is the property and real estate sector companies listed on the Indonesia Stock Exchange in 2009-2017. This study uses a purposive sampling technique in determining research samples. the number of companies selected as the study sample were 18 companies registered in the property and real estate sector. This study uses a quantitative approach. The results showed that partially growth opportunity and size had not significant effect, while profitability and business risk had a significant effect on capital structure. the results of testing simultaneously growth opportunity, profitability, business risk, and size have a significant influence on the capital structure.

Turn Over ratio, Gross Profit Margin and Return On Equity show unfavorable conditions. 


\section{A. Pendahuluan}

Bisnis property dan real estate dewasa kini menjadi bisnis yang sangat menjajikan bagi masyarakat, karena harga property selalu mengalami pertumbuhan setaip tahunnya. Kenaikan tersebut bisa di karenakan oleh faktor supply dan demand , inflasi dan juga pertumbuhan penduduk yang semakin meningkat. Faktor tersebut menjadi peluang tersendiri bagi industri property dan real estate sehingga industri tersebut semakin hari semakin bertumbuh. Perusahaan yang mengalami pertumbuhan akan membutuhkan modal yang lebih besar untuk membiayai operasioal perusahaan. Modal tersebut bisa bersumber dari internal ataupun eksternal perusahaan. besarnya modal yang di butuhkan dapat di tentukan melalui kebijakan struktur modal perusahaan.

Keputusan pendanaan bagi perusahaan merupakan hal yang sangat penting. Karena kuatnya struktur modal akan memudahkan perusahaan dalam membelanjai segala aktivitas perusahaan. Irham Fahmi (2012, p. 178) salah satu faktor yang membuat perusahaan memiliki daya saing jangka panjang karena faktor kuatnya struktur modal yang dimiliki perusahaan. kuatnya modal yang di miliki perusahaan akan memudahkan perusahaan dalam membiayai investasi-investasi baru yang menguntungkan bagi perusahaandi masa mendatang. Modal tersebut bisa di himpun baik dari utang ataupun ekuitas.

Penggunaan utang dalam struktur modal di harapkan dapat meningkatkan expected return bagi saham perusahaan. akan tetapi jika rasio utang lebih besar dari biaya modal yang di gunakan di khawatirkan akan meningkatkan beban bunga dan menyebabkan perusahaan mengalami financial distress, sementara jika perusahaan menerbitkan saham maka akan menimbulkan cost of equity yang berupa deviden. Untuk menghindari risiko financial distress, maka perlu di lakukan peninjauan faktorfaktor yang mempengaruhi keputusan struktur modal agar tercipta komposisi struktur modal yang optimal. Brigham dan Houston (2011, p. 155) Struktur modal yang optimal harus berada pada keseimbangan antara risiko dan pengembalian yang memaksimalkan harga sahamnya. Menurut Aydin Ozkan (2001) menyatakan bahwa struktur modal berkembang secara dinamis dan berubah dari waktu ke waktu, akibatnya selalu terjadi perubahan struktur modal dan juga faktor-faktor yang mempengaruhinya, hal ini disebabkan karena dalam operasional perusahaan selalu terjadi berbagai kepentingan berkenaan pendanaan yang berakibat pada dinamika DER. Dengan demikian maka perlu diteliti faktor-faktor apa saja yang mempengaruhinya.

Sugiarto (2009, p. 120),"Variabel-variabel yang terkait dengan struktur modal adalah ukuran perusahaan (firm size), kesempatan tumbuh di masa depan (growth opportunity), kemampulabaan (profitability), risiko bisnis (business risk), effective tax rate, keberwujudan aset (asset tangibility), umur perusahaan (firm age), liquidity dan jenis industri.

Variabel pertama pada penelitian ini adalah growth opportunity. Agus Sartono (2012, p. 248) Tingkat pertumbuhan perusahaan semakin cepat pertumbuhan perusahaan maka semakin besar kebutuhan dana untuk pembiayaan ekspansi. Semakin besar kebutuhan untuk pembiayaan mendatang maka semakin besar keinginan perusahaan untuk menahan laba. Variabel kedua adalah profitability. Menurut Brigham dan Houston (2010, p. 189). Perusahaan dengan return on assets yang tinggi, umumnya menggunakan hutang dalam jumlah yang relatif kecil, karena dengan rate of return yang tinggi, kebutuhan dana dihasilkan secara internal dari laba ditahan. 
Variabel ketiga adalah business risk. Business risk adalah ketidakpastian yang ada pada suatu proyeksi pengembalian di masa yang akan datang. Menurut Brigham dan Houston (2013, p. 157) terdapat dua dimensi risiko, yaitu risiko keuangan (financial risk) serta risiko bisnis/risiko usaha (business risk). Risiko keuangan merupakan risiko tambahan bagi pemegang sahambiasa karena perusahaan menggunakan hutang. Peusahaan yang mempunyai risiko bisnis yang tinggi harus menyadari bahwa penggunaan utang akan menambah risiko bagi perusahaan, terutama saat bunga yang menjadi kompensasi atas pinjaman menjadi naik. Variabel keempat adalah firm size. Menurut J.P Sitanggang (2013, p. 76) menyatakan bahwa perusahaan besar memiliki kemudahan dalam memperoleh sumber dana eksternal. Sealin itu juga semakin besar suatu perusahaan maka dana yang di butuhkan untuk menjalankan operasionalnya akan semakin besar.

Berdasarkan pemaparan di atas, penulis tertarik untuk melakukan pengujian terhadap variable-variabel yang berkaitan dengan struktur modal, dengan judul "Pengaruh Growth Opportunity, Profitability, Business Risk Dan Size Terhadap Struktur Modal" (Studi Pada Perusahaan Property dan Real Estate Yang Terdaftar Di BEI Periode 2009-2017).

\section{B. Perumusan Masalah}

Berdasarkan latar belakang masalah di atas maka dapat di rumuskan sebagai berikut:

1. Bagaimana pengaruh growth opportunity terhadap struktur modal ?

2. Bagaimana pengaruh profitability terhadap struktur modal ?

3. Bagaimana pengaruh business risk terhadap struktur modal ?

4. Bagaimana pengaruh firm size terhadap struktur modal ?

5. Bagaimana pengaruh growth opportunity, profitability, business risk, dan firm size secara simultan terhadap struktur modal ?

\section{Tujuan Penelitian}

1. Untuk menganalisis pengaruh growth opportunity terhadap struktur modal.

2. Untuk menganalisis pengaruh profitability terhadap struktur modal.

3. Untuk menganalisis pengaruh business risk terhadap struktur modal.

4. Untuk menganalisis pengaruh size terhadap terhadap struktur modal.

5. Untuk menganalisis pengaruh growth opportunity, profitability, business risk, dan firm size secara simultan terhadap struktur modal ?

\section{Landasan Teori}

\section{Struktur Modal}

Van Horne dan Wachowicz (2013, p. 176) mendefinisikan struktur modal adalah bauran atau proporsi pendanaan permanen jangka panjang perusahaan yang diwakili oleh hutang, saham preferen dan ekuitas saham biasa. Menurut Agus Sartono (2010, p. 225) didefinisikan sebagai berikut: "Struktur modal merupakan perimbangan jumlah utang jangka pendek yang bersifat permanen, utang jangka panjang, saham preferen dan saham biasa." Struktur modal memberikan gambaran bagi perusahaan tentang bagai mana operasional perusahaan tersebut di biayai dengan tujuan untuk memaksimalkan nilai perusahaan.

\section{Struktur Modal Optimal}

Menurut Farah Margaretha (2011, p. 112) "Struktur modal yang optimal adalah struktur modal yang mengoptimalkan keseimbangan antara risiko dan tingkat pengembalian sehingga memaksimalkan harga saham"

\section{Teori Struktur Modal}

a. Pendekatan Tradisional 
Pendekatan tradisional berpendapat akan adanya struktur modal yang optimal, yakni struktur modal yang mempunyai pengaruh terhadap nilai perusahaan. Komposisi struktur modal bisa di ubah-ubah agar bisa di peroleh nilai perusahaan yang optimal.

b. Pendekatan Modigiani Miller Tanpa Pajak

Modigliani dan Miller menyimpulkan bahwa nilai perusahaan yang menggunakan utang lebih tinggi daripada perusahaan yang tidak menggunakan utang. Terdapat dua proposisi dalam teori MM tanpa pajak yaitu: pertama, jika tidak ada pajak nilai perusahaan tidak tergantung pada leverage. Kedua, jika utang yang digunakan bertambah, risiko perusahaan juga bertambah sehingga biaya modal sendiri atau keuntungan yang disyaratkan pada modal sendiri meningkat (Setyawan, Topowijono, \& Nuzula, 2016).

c. Pendekatan Modigliani Miller dengan Pajak

Karena pendekatan MM tanpa pajak di anggap tidak relevan, kemudian Modigliani dan Miller memasukan faktor pajak kedalam penelitian mereka. Teori tersebut berpendapat bahwa interest bisa di gunakan untuk menghemat pajak. Teori tersebut mempunyai dua proporsi yaitu : pertama,perusahaan yang sama sekali tidak mengguanakan utang berarti sama dengan modal perusahaan. kedua, pembiayaan dengan hutang sangat menguntungkan dan MM menyatakan bahwa struktur modal optimal perusahaan adalah $100 \%$ hutang.

d. Pendekatan Agency Theory

Menurut Lukas S. Atmaja (2008, p. 13). Teori keagenan (agency theory) ditekankan untuk mengatasi dua permasalahan yang dapat terjadi dalam hubungan keagenanDalam pendekatan ini struktur modal bertujuan untuk mengurangi konflik berbagai kepentingan. Karena manajer ingin menahan sumber dana, sementara principal ingin mengeluarkan dana. Penggunaan struktur modal di maksudkan agar manajer bisa mengeluarkan dana.

e. Pendekatan Trade Off

Teori Trade Off menjelaskan penukaran manfaat pajak dengan penggunaan utang serta masalah yang timbul dari potensi kebangkrutan. Struktur modal yang optimal dapat di bentuk dengan menyeimbangkan keuntungan pengguanaan utang dengan potensi kebangkrutan dan agency problem.

f. Teori Sinyal

Teori sinyal adalah tindakan yang di lakukan manajemen dalam memberikan petunjuk bagi pihak luar tentang prospek perusahaan di masa mendatang. Perusahaan yang mempunyai prospek tinggi akan lebih suka menggunakan utang daripada menerbitkan saham baru.

g. Pendekatan Peckig Order

Teori pecking order bertujuan untuk memberikan gambaran mengenai hirarki dalam menentuka sumber modal. di mulai dari yang beresiko paling rendah hingga yang mempunyai risiko tinggi. teori ini menyatakan bahwa perusahaan yang mempunyai profitabilitas tinggi mempunyai utang yang rendah karena perusahaan lebih suka mendanai investasinya mengguanakan laba di tahan yang berasal dari profit perusahaaan.

4. Hubungan Faktor-Faktor Struktur Modal

a. Hubungan Growth Opportunity dengan Struktur Modal

Menurut Brigham dan Houston (2011, p. 189) Apabila tingkat pertumbuhan perusahaan cepat dapat berdampak pada kebutuhan pendanaan yang semakin besar Perusahaan yang bertumbuh pesat cenderung lebih 
b. Hubungan Profitability dengan Struktur Modal

Myers (1984) dengan pecking order theory-nya mengungkapkan bahwa ada pengaruh negatif antara profitabilitas dengan strktur modal. Karena, perusahaan yang mempunyai profit yang tinggi akan lebih mudah untuk menggunakan dana yang berasal dari laba usaha dan juga dari sumber internal perusahaan.

c. Hubungan Business Risk dengan Struktur Modal

Risiko bisnis adalah ketidakpastian yang melekat dalam suatu usaha, semakin beresiko suatu usaha maka akan semakin beresiko penggunaan utang dalam komposisi struktur modal.

d. Hubungan Firm Size dengan Struktur Modal

Menurut J.P Sitanggang (2013, p. 76$)$ menyatakan bahwa perusahaan besar memiliki kemudahan dalam memperoleh sumber dana eksternal. Oleh karena itu, perusahaan besar akan memiliki struktur modal yang lebih besar dibandingkan perusahaan kecil dikarenakan semakin besar ukuran perusahaan, terdapat kecenderungan untuk menggunakan utang yang lebih besar.

\section{E. Metodologi Penelitian}

Lokasi pada penelitian ini adalah Galeri Bursa Efek Indonesia dengan mengambil objek penelitian pada perusahaan yang bergerak di sektor properti dan real estate Waktu pada penelitian ini mengambil jarak antara tahun 2009-2017. Adapun perusahaan properti dan real estate yang terdaftar di bursa efek Indonesia ada 48 perusahaan. Pemilihan sampel penelitian dilakukan berdasarkan metode purposive sampling, yaitu penentuan sampel berdasarkan kriteria tertentu sesuai dengan yang dikehendaki oleh peneliti. Adapun kriteria yang digunakan disini ada beberapa.

1. perusahaan telah ter- daftar di Bursa Efek Indonesia pada sektor properti dan real estate sejak bulan Januari 2009.

2. perusahaan tetap listing sampai Desember 2017.

3. perusahaan tidak pernah dilakukan suspend maupun delisting atau keluar dari sektor property dan real estate selama Januari 2009 sampai Desember 2017.

4. perusaha-an memiliki laporan keuangan per 31 Desember setiap tahunnya.

5. Selama tahun 2009-2017 laba bersih perusahaan tidak boleh negatif.

6. Perusahaan yang mempunyai data pasar (historical prices) yang lengkap setiap periodenya

\begin{tabular}{|c|l|c|}
\hline NO & \multicolumn{1}{|c|}{ Nama Perusahaan } & KODE \\
\hline 1 & PT. Alam Sutera Realty Tbk & ASRI \\
\hline 2 & PT. Bekasi Asri PemulaTbk & BAPA \\
\hline 3 & PT. Bukit Sentul CityTbk & BKSL \\
\hline 4 & PT. Bumi Serpong Damai Tbk & BSDE \\
\hline 5 & PT. Ciputra Surya Tbk & CTRA \\
\hline 6 & PT. Duta Anggada Realty Tbk & DART \\
\hline 7 & PT. Intiland Development Tbk & DILD \\
\hline 8 & PT. Duta Pertiwi Tbk & DUTI \\
\hline
\end{tabular}




\begin{tabular}{|c|l|c|}
\hline 9 & PT. Gowa Makkasar Tourism Development Tbk & GMTD \\
\hline 10 & PT. Jaya Property Tbk & JRPT \\
\hline 11 & PT. Kawasan Industri Jababeka Tbk & KIJA \\
\hline 12 & PT. Lippo Cikarang Tbk & LPCK \\
\hline 13 & PT. Lippo Karawaci Tbk & LPKR \\
\hline 14 & PT. Modernland Realty Tbk & MDLN \\
\hline 15 & PT. Pudjiati Prestige Tbk & PUDP \\
\hline 16 & PT. Pakuwon Jati Tbk & PWON \\
\hline 17 & PT. Dadanayasa Arthatama Tbk & SCBD \\
\hline 18 & PT. Summarecon AgungTbk & SMRA \\
\hline
\end{tabular}

Sumber : Bursa Efek Indonesia

Variabel yang di gunakan dalam penelitian ini terdiri variabel independen $(X)$ dan variabel dependen $(\mathrm{Y})$. Gambaran variabel penelitian dapat di uraikan sebagai berikut :

1. Variabel Independen

- Growth Opportunity

Di hitung dengan perubahan pertumbuhan asset dengan rumus :

$$
\operatorname{AGR}=\frac{T A(t)-T A(t-1)}{T A(t-1)}
$$

- Profitability

Di hitung dengan mengguanakan rasio Return on Asset (ROA) :

$$
R O A=\frac{\text { EAT }}{\text { TA }}
$$

- Business Risk

Dihitung dengan menggunakan deviasi standar ROE dengan rumus sebagai berikut :

$$
\text { BRISK }==\frac{\sigma \text { EAT }}{\text { Equity }}
$$

- Firm Size

Dapat di ukur dengan menggunakan logaritma natural dari total asset perusahaan.

\section{SIZE = LN (TOTAL ASSET)}

2. Variabel Dependen

Variabel dependen di ukur dengan menggunakan rasio debt to equity ratio (DER) dengan rumus sebagai berikut :

\section{Total Debt}

\section{DER=}

Total Equity 


\section{F. Hasil Dan Pembahasan}

Hasil

\section{Deskripsi Statistik}

Deskripsi statistik pengaruh growth opportunity, profitability, business risk, dan firm size terhadap struktur modal yang terdaftar di Bursa Efek Indonesia periode 20092017 adalah sebagai berikut :

\begin{tabular}{|c|c|c|c|c|c|}
\hline & DER & AGR & BRISK & ROA & SIZE \\
\hline Mean & 0.944580 & 19.31777 & 0.084235 & 6.131978 & 29.24783 \\
\hline Median & 0.840254 & 12.10088 & 0.067467 & 5.328098 & 29.44697 \\
\hline Maximum & 3.827529 & 118.9615 & 0.479336 & 31.61060 & 31.67007 \\
\hline Minimum & 0.151451 & -20.27139 & 0.000761 & 0.133024 & 25.62768 \\
\hline Std. Dev. & 0.559039 & 23.68268 & 0.068792 & 4.647231 & 1.405776 \\
\hline Skewness & 1.505332 & 2.236472 & 2.176450 & 2.141127 & -0.983107 \\
\hline Kurtosis & 7.057100 & 8.728170 & 10.60419 & 10.27926 & 3.431762 \\
\hline Jarque-Bera & 172.2881 & 356.5293 & 518.2077 & 481.4460 & 27.35382 \\
\hline Probability & 0.000000 & 0.000000 & 0.000000 & 0.000000 & 0.000001 \\
\hline Sum & 153.0220 & 3129.479 & 13.64610 & 993.3805 & 4738.148 \\
\hline $\begin{array}{l}\text { Sum Sq. } \\
\text { Dev. }\end{array}$ & 50.31654 & 90299.96 & 0.761918 & 3477.078 & 318.1693 \\
\hline $\begin{array}{l}\text { Observation } \\
\mathrm{s}\end{array}$ & 162 & 162 & 162 & 162 & 162 \\
\hline
\end{tabular}

\section{Determinan Struktur Modal}

Dalam melakukan pemilihan model di lakukan tiga pengujian yaitu : Pertama, melakukan uji chow test untuk memilih antara model antara common effect model dan fixed effect model. Kedua, melakukan uji hasuman test untuk membandingkan antara model fixed effect dan random effect. Ketiga, jika di perlukan maka akan di gunakan lagrange multiplier test untuk membandingkan antara common effect dan random effect. Dari hasil pengujian maka dapat di peroleh kesimpulan sebagai berikut :

\begin{tabular}{|c|l|l|l|}
\hline NO & \multicolumn{1}{|c|}{ METODE } & \multicolumn{1}{|c|}{ PENGUJIAN } & HASIL \\
\hline 1. & Uji Chow Test & $\begin{array}{l}\text { Common Effect vs Fixed } \\
\text { Effect }\end{array}$ & Fixed Effect \\
\hline 2. & Uji Hausman Test & $\begin{array}{l}\text { Fixed Effect vs Random } \\
\text { Effect }\end{array}$ & Fixed Effect \\
\hline
\end{tabular}

Estimasi Model Regresi Data Panel (pool data) secara Parsial (Uji $T$ ) dan

Simultan (Uji F) dengan fixed effect model : 
Dependent Variable: DER

Method: Panel Least Squares

Date: 07/09/19 Time: 18:34

Sample: 20092017

Periods included: 9

Cross-sections included: 18

Total panel (balanced) observations: 162

\begin{tabular}{crrrr}
\hline \hline \multicolumn{1}{c}{ Variable } & Coefficient & Std. Error & t-Statistic & Prob. \\
\hline \hline C & 1.590989 & 1.705945 & 0.932615 & 0.3526 \\
RGR & -0.000722 & 0.001368 & -0.527892 & 0.5984 \\
BRISK & -0.113622 & 0.018437 & -6.162720 & 0.0000 \\
SIZE & 8.214225 & 1.366946 & 6.009180 & 0.0000 \\
& -0.021460 & 0.058458 & -0.367101 & 0.7141 \\
\hline \hline & Effects Specification & & \\
Cross-section fixed (dummy variables) & & & \\
\hline \hline R-squared & 0.637770 & Mean dependent var & 0.944580 \\
Adjusted R-squared & 0.583435 & S.D. dependent var & 0.559039 \\
S.E. of regression & 0.360814 & Akaike info criterion & 0.924744 \\
Sum squared resid & 18.22616 & Schwarz criterion & 1.344047 \\
Log likelihood & -52.90423 & Hannan-Quinn criter. & 1.094987 \\
F-statistic & 11.73785 & Durbin-Watson stat & 0.804004 \\
Prob(F-statistic) & 0.000000 & & \\
\hline \hline
\end{tabular}

Hasil Estimasi Regresi Data Panel (Pool Data) :

\begin{tabular}{|c|c|c|c|c|}
\hline \multirow{2}{*}{ Model } & Ajusted $\mathbf{R}^{\mathbf{2}}$ & $\begin{array}{c}\text { Probabilit } \\
\text { as }(\boldsymbol{F} \\
\text { Stat.) } \mathbf{\alpha}- \\
\mathbf{0 , 0 5}\end{array}$ & \multicolumn{2}{|c|}{ Probabilitas $\mathbf{\alpha}-\mathbf{0 , 0 5}$} \\
\hline \multirow{2}{*}{$\begin{array}{c}\text { Fixed } \\
\text { Effect }\end{array}$} & 0,637770 & \multirow{2}{*}{0,000000} & $A G R$ & Tidak Signifikan \\
\cline { 4 - 5 } & & & $R O A$ & Signifikan \\
\cline { 3 - 5 } & & & SISE & Signifikan \\
\cline { 3 - 5 } & & & &
\end{tabular}

\section{G. Kesimpulan}

1. Growth Opportunity (AGR) secara parsial berpengaruh negatif dan tidak signifikan terhadap Debt to Equity Ratio (DER) dengan demikian variabel AGR tidak berpengaruh terhadap struktur modal perusahaan property dan real estate yang terdaftar di Bursa Efek Indonesia periode 2009-2017.

2. Return on Asset (ROA) secara parsial berpengaruh negatif dan signifikan terhadap Debt to Equity Ratio (DER) dengan demikian variabel ROA mempengaruhi struktur modal perusahaan property dan real estate yang terdaftar di Bursa Efek Indonesia periode 2009-2017.

3. Business Risk (BRISK) secara parsial berpengaruh positif dan signifikan terhadap Debt to Equity Ratio (DER) dengan demikian variabel BRISK 
mempengaruhi struktur modal perusahaan property dan real estate yang terdaftar di Bursa Efek Indonesia periode 2009-2017.

4. Firm Size (SIZE) secara parsial berpengaruh negatif dan tidak signifikan terhadap Debt to Equity Ratio (DER) dengan demikian variabel SIZE tidak mempengaruhi struktur modal perusahaan property dan real estate yang terdaftar di Bursa Efek Indonesia periode 2009-2017.

5. Variabel AGR, ROA, BRISK dan SIZE berpengaruh secara simultan terhadap Debt to Equity Ratio (DER) pada perusahaan property dan real estate yang terdaftar di Bursa Efek Indonesia periode 2009-2017. Dan dapat menjelaskan variabel struktur modal yang di proksikan dengan Debt to Equity Ratio (DER) sebesar 0,637770 atau 63 persen. Sementara sisanya 37 persen di pengaruhi oleh faktor lain yang tidak terdapat dalam penelitian tersebut.

\section{H. Saran}

\section{Bagi Manajemen Perusahaan}

Pihak manajemen perusahaan di sarankan untuk meninjau faktor-faktor yang berkaitan dengan struktur modal yaitu growth opportunity, profitability, business risk, dan size sebagai bahan pertimbangan dalam menentukan komposisi struktur modal yang optimal. Dengan tujuan akhir adalah untuk memaksimalkan nilai perusahaan.

\section{Bagi Investor}

Bagi para investor di sarankan untuk meninjau faktor-faktor yang berkaitan dengan struktur modal yaitu growth opportunity, profitability, business risk, dan size. Investor diharapkan dapat memperhatikan variabel-variabel tersebut sebagai pertimbangan sebelum mengambil keputusan dalam melakukan investasi.

\section{Bagi Kreditur}

Bagi pihak kreditur di sarankan untuk meninjau faktor-faktor yang berkitan dengan struktur modal yaitu growth opportunity, profitability, business risk, dan size. Bisa menjadi pertimbangan bagi pihak kreditur sebelum memberikan kredit kepada perusahaan.

\section{Bagi Peneliti Selanjunya}

a. Peneliti selanjutnya disarankan untuk menggunakan periode yang lebih panjang dan terbaru, agar mendapatkan hasil yang lebih update. Agar hasil penelitian lebih akurat dan tingkat kepastian semakin benar.

b. Peneliti selanjunya di sarakan untuk menambah variabel-variabel struktur modal seperti tangibility, umur perusahaan, stabilitas penjualan, sikap manajemen, dan variabel lainnya, sehingga penelitian tidak terbatas hanya menggunakan variabel yang ada dalam penelitian ini. Tujuannya agar dapat di peroleh gambaran yang jelas mengenai variabel-variabel yang menetukan struktur modal. 


\section{DAFTAR PUSTAKA}

Atmaja, L. S. (2008). Teori dan praktik Manajemen Keuangan. Yogyakarta: Andi.

Brigham, e. F., \& Houston, J. F. (2011). dasar-dasar manajemen keuangan : Edisi 10. Jakarta: salemba empat.

Fahmi, I. (2012). Analisis Laporan Keuangan. Bandung: Alfabeta.

Hanafi, M. M. (2016). Manajemen Keuangan, Edisi 2 Cetakan Pertama. Yogyakarta: BPFE.

Kadim, A., \& Sunardi, N. (2019, May). Eviews Analysis; Determinan Tourism, Restaurant and Hotel Company's Soundness and Performance. In Proceeding Interuniversity Forum for Strengthening Academic Competency (Vol. 1, No. 1, pp. 332-340).

Kasmir. (2010). Analisis Lapora Keuangan. Jakarta: Rajawali Pers.

Kasmir. 2010. Pengantar Manajemen Keuangan. Edisi 1. Kencana Prenada Media Group:Jakarta

Kasmir. 2012. Analisis Laporan Keuangan, Edisi Ke 4. Rajagrafindo Persada:Jakarta

Kasmir. 2015. Analisis Laporan Keuangan, Edisi Ke 7. Rajagrafindo Persada:Jakarta

Margaretha, F. (2011). Manajemen Keuangan Untuk Manajer Nonkeuangan. Jakarta: Erlangga.

Munawir, S. 2010. Analisis Laporan Keuangan Edisikeempat. Cetakan kelima Belas. Liberty: Yogyakarta

Myers, S. C. (1984). The Capital Structure Puzzle. Journal of Finance. Vol. 39, 581-582.

Nurmasari, I. 2017. Analisis Current Ratio, Return On Equity, Debt to Equity Ratio dan Pertumbuhan Pendapatan Berpengaruh Terhadap Return Saham Pada Perusahaan Pertambangan Di Bursa Efek Indonesia 2010-2014. Jurnal Kreatif, 5(1), 112-131.

Okzan, A. (2001). determinants of capital structure and Adjustment to Long Run Target : Evidence from UK Company Panel Data. Journal Business Finance and Accounting.

Rudianto. 2012. Akuntansi Pegantar. Salemba Empat: Jakarta

Sartono, A. (2010). Manajemen Keuangan Edisi Empat . Yogyakarta: BPFE.

Setyawan, A. W., Topowijono, \& Nuzula, N. F. (2016). Pengaruh firm size, growth opportunity, profitability, business risk, effective tax rate, asset tangibility, firm age dan liquidity terhadap struktur modal perusahaan. JurnalAdministrasi Bisnis (JAB)/Vol.31 No.1 Februari 2016.

Sitanggang, J. P. (2013). Manajemen Keuangan Perusahaan Lanjutan . Jakarta: Mitra Wacana Media. 
Sugiarto. (2009). Struktur Modal, Struktur kepemilikan perusahaan,permasalahan ke agenan \& informasi asimetri (edisi pertama ed.). Yogyakarta: Graha Ilmu.

Sugiono, A., dan Untung, E. 2010. Panduan Praktis Dasar Analisis Laporan Keuangan. PT Grasindo. Jakarta

Sugiono. 2016. Metode Penelitian Kuantitatif Kualitatif dan R\&D. Edisi Ke 23. Alfabeta: Jakarta

Sunardi, N. (2018). Analisis Du Pont System Dengan Time Series Approach (Tsa) Dan Cross Sectional Approach (Csa) Dalam Penilaian Kinerja Keuangan Perusahaan (Studi Pada Industri Konstruksi (BUMN) di Indonesia Yang Listing di BEI Tahun 2013-2017). Jurnal SEKURITAS (Saham, Ekonomi, Keuangan dan Investasi), 1(4).

Sunardi, N. (2019). Determinan Intelectual Capital dengan Pendekatan iB-VAIC ${ }^{\mathrm{TM}}$ Terhadap Efisiensi Biaya Implikasinya Pada Profitabilitas Perbankan Syariah di Indonesia. JIMF (Jurnal IImiah Manajemen Forkamma), 1(1).

Sunardi, N., \& Sasmita, A. S. (2019). Pengaruh Likuiditas, Leverage Dan Growth Terhadap Kinerja Industri Makanan Dan Minuman Yang Tercatat Di Indonesia Stock Exchange Selama Periode Tahun 2011-2015. Jurnal Sekuritas (Saham, Ekonomi, Keuangan dan Investasi), 2(2), 81-97.

Sunardi, N., Hamid, A. A., Lativa, A. K., \& Tulus, N. (2018). Determinant Of Cost Efficiency And It's Implications For Companies Performance Incorporated In The Lq. 45 Index Listing In Idx For The Period of 2011-2016. International Journal of Applied Business and Economic Research, 16(1).

Usman, H. 2013. Manajemen: Teori Praktik dan Riset Pendidikan. Edisi ke 4. Bumi Aksara: Jakarta

Van Horne, \& Wachowich. (2013). Prinsip-Prinsip Manajemen Keuangan, Edisi12, Buku 2. Jakarta: Salemba Empat.

Weston, J. F., \& Brigham, E. F. (2010). Manajemen Keuangan, Edisi ke-III. Jakarta: Salemba Empat. 